\title{
Usos y costumbres del peritaje antropológico
}

\author{
YURI ESCALANTE BETANCOURT
}

\section{Customs and Habits from Anthropologist Expert Witness}

\section{YURI ESCALANTE BETANCOURT Investigador independiente yuriescala@yahoo.com.mx}

Desacatos 57 mayo-agosto 2018, pp. 72-81 n un artículo premonitorio, publicado en 1989, Claude LéviStrauss (2014) auguraba que la incursión de la etnología en el campo del derecho produciría un quiebre en la teoría, metodología y espíritu de la disciplina. Con notoria perspicacia, observaba que al participar como expertos en litigios jurídicos, nuestro campo de investigación ya no era lo exótico, sino lo tedioso de los expedientes, que el objeto de estudio no se enfocaba en los pueblos lejanos, sino en lo cercano de nuestra sociedad, y que en lugar contratar informantes, ellos ahora nos contrataban a nosotros para defenderlos.

Los ensayos compilados en este número de Desacatos muestran algunos de estos cambios epistemológicos ocurridos por la incursión de la antropología en el campo legal. En estas líneas pretendo dar testimonio de los usos y costumbres que surgen en la investigación antropológica al elaborar informes periciales a solicitud de los órganos judiciales. Se trata de explorar ciertas prácticas, hábitos, tendencias e ideas recurrentes en la producción de dictámenes, de las que el propio perito, en ocasiones, no está seguro de su validez o eficacia.

De hecho, dado que la función principal del perito radica en ser auxiliar del aparato judicial o de una de las partes, el ideal de la investigación pura se desestabiliza y las fronteras entre antropólogo y sujeto de estudio, o entre investigador y actor social, se relativizan. Por ello el peritaje, al perfilarse como una modalidad de la antropología aplicada, desde fuera se ve como un oficio menor, incompleto o bastardo. Por sus técnicas de investigación y narrativa de exposición, incluso suele negarse su estatus de cientificidad.

Lo que aquí llamamos usos y costumbres son precisamente esas formas de explorar y redactar el peritaje que no cuadran con las normas clásicas de la antropología, como aminorar la observación participante, invertir poco tiempo en la empatía, argumentar más que interpretar y afirmar más que narrar.

Estos desplazamientos e inestabilidades crean inseguridad, preocupaciones y autojustificaciones que se reflejan en los textos aquí 
reunidos. Es lo que Rosalva Aída Hernández Castillo ha llamado "la ansiedad del perito". En las siguientes líneas revisaremos algunas de estas preocupaciones y reflexiones.

\section{Los orígenes}

A propósito de la inseguridad y ansiedad que provoca la redacción de dictámenes periciales con una metodología no canónica, Héctor Ortiz Elizondo comienza su colaboración llamando la atención sobre el trabajo criminológico que hicieron los fundadores de la disciplina en el siglo XIX. Su interés se dirige a desacreditar la falacia de entender la antropología como un conocimiento lineal destinado a la investigación de campo, que tendría como tierra prometida ese objeto del deseo llamado cultura. Lo que postula es que en paralelo a la pretensión de conocer el desarrollo evolutivo de la civilización, los antropólogos también se concentraron en la investigación de hechos y motivos delictivos. Es decir, que el análisis del carácter de los pueblos y los individuos estuvo antes de que predominaran los temas culturales, simbólicos o de significado.

El apunte de Ortiz Elizondo no sólo desacreditaría el purismo epistemológico del saber antropológico. Lo que sostiene es que, tras bambalinas, la antropología cultural y social siempre ha realizado un trabajo de la personalidad emparentado con la criminología. Que ya había y aún existe un abanico de objetos cuya tradición no podemos ocultar. Pero el llamado de Ortiz Elizondo no sólo puede aplicarse a los fundadores de la disciplina, sino también al caso mexicano.

En otro lugar he resaltado que los antecedentes de la antropología mexicana y de la antropología jurídica deben buscarse en los abogados, criminólogos y sociólogos de principios del siglo Xx, como Lucio Mendieta, Franco Sodi, y en especial, los juristas que publicaron la revista Criminalia (Escalante, 2015). Fueron ellos los primeros que se mostraron escépticos del monismo jurídico y analizaron la ley y conductas o prácticas consuetudinarias.

El debate y la escuela que estos juristas establecieron tuvo bastantes secuelas. Hoy resulta pertinente recordarlo porque fue el fundamento para las investigaciones de Manuel Gamio, Ramón Mena y Gonzalo Aguirre Beltrán. Ellos, además de sentar los precedentes de la arqueología y el indigenismo, hicieron estudios de derecho comparado. En el caso de Gamio y Mena, no sólo incursionaron en la investigación criminológica sino que desempeñaron cargos de magistrado y juez, respectivamente. A contracorriente de la antropología social y del relativismo cultural, estos autores privilegiaban el derecho comparado y el estudio de las relaciones entre sociedades.

De ahí que José Castillo Farreras (1973) sostenga que Manuel Gamio no sólo es el precursor del indigenismo, sino también del peritaje antropológico. Algo hay de cierto en ello, si consideramos que Gamio y Mena sostuvieron litigios personales y confrontaron peritajes por diferendos en la falsificación de piezas, pero sobre todo porque Gamio, como magistrado, trabajaba en las penitenciarías y formuló metodologías sobre estudios criminológicos, dictámenes antropométricos, ensayos sobre heterogeneidad jurídica y una crítica insistente a la aplicación general de la ley, sobre todo en un caso de brujería en el que el homicida fue condenado a muerte (Mena, 1903). ${ }^{1}$

En resumen, la antropología, a pesar de su obsesión por la cultura y lo colectivo, nunca ha sido ajena a lo conductual y criminal. Lo anterior no significa que

AMG, sección Producción intelectual, serie Artículos, "Algunas sugestiones para la investigación sociológica de los delincuentes con referencia especial a los cuestionarios individuales", caja 2, exp. 229; "Informe siquiátrico sobre investigaciones relativas a prevención social que han estado haciendo en el Consejo por la sección de sociología", caja 4, exp. 405; "Los que viven en otro mundo. Problemas legales de heterogeneidad social”, caja 4, exp. 230. 
sea la otra cara de la moneda y se constituya como una disciplina forense. Deslindarse de la ortodoxia de ninguna manera implica que exista una antropología de segunda o una antropología sin método o teoría.

En realidad, la observación que podría hacerse al escrito de Ortiz Elizondo radica en que el peritaje antropológico, si bien se origina y no ha dejado de vincularse a lo criminal, encaminarlo a dicho campo y a la primacía de las conductas y los motivos también resultaría limitante. Estaríamos llevando el proyecto antropológico hacia la psiquiatrización del sujeto, peligro que Foucault (2001) advirtió al desenmascarar los informes periciales sobre inimputabilidad.

Por el contario, el peritaje antropológico ha tomado otros vuelos en los últimos años. Viene a cuento recordar a uno de los precursores citados por Ortiz Elizondo en este volumen: Lewis Morgan (Holmes, 1907). No sólo fue el pionero del evolucionismo y el materialismo, de la lingüística y el parentesco, de la pluralidad legal y política presente en los pueblos de América. También fue el primer abogado-etnólogo que litigó y presentó pruebas para defender el territorio despojado a los iroqueses.

La repercusión de este acto fue una serie de reclamaciones de tierras que ocasionaron la investigación sobre la posesión territorial de los pueblos de Norteamérica, al grado de que a mediados del siglo pasado se conformara la disciplina que ahora conocemos como etnohistoria (Martínez, 1976). En México, la etnohistoria ha jugado un papel similar dentro del derecho agrario y la recuperación de tierras por medio del análisis de códices, crónicas y documentos coloniales, desde Joaquín Galarza (1979) hasta Francisco Lara. ${ }^{2}$

No es fortuito referir la trayectoria del peritaje — criminal y territorial — dentro de la antropología, ya que si bien no ha sido sistematizada, es a todas luces una tradición y una costumbre disciplinar vinculada de cerca a las controversias legales y expedientes judiciales derivados de la imposición del derecho positivo a las minorías nacionales.
Hernández Castillo y Ortiz Elizondo (2012) ofrecen justamente uno de los intentos mejor logrados de llevar los estudios periciales del ámbito criminal al territorial. En un dictamen presentado ante la Corte Interamericana de Derechos Humanos (CIDH), aunque de fondo hay un asunto de barbarie penal - la violación de dos mujeres por miembros del ejército-, el estudio se enfoca más bien en evidenciar la desarticulación sociocultural ocasionada por la ocupación militar, disloque provocado por la ocupación permanente del ejército y vivido por los afectados bajo la etiología del "susto".

El susto entendido no sólo como enfermedad psicosomática, sino como un estado de inseguridad generalizada que afecta la vida colectiva por una ocupación continua del territorio y que la Corte calificó como "violencia institucional castrense". Por ello, el peritaje propone como medida de reparación el retiro de las tropas del ejército.

Traigo a colación la investigación de dos de los participantes en este número para insistir en que lo penal y lo criminal, desde el punto de vista de la antropología, se deslizan con persistencia hacia lo colectivo, lo territorial, lo jurisdiccional, pero finalmente hacia la reconstitución del poder jurídico y político de los pueblos. Lo penal y lo criminal, por lo tanto, desbordan a su vez la antropología y el derecho para ir más allá de la cultura y los símbolos, y anclarse en lo político y territorial. Mas ahora ya no estamos hablando de orígenes y pasados, sino de presentes y futuros.

\section{Los territorios}

Aunque la legislación en materia de derechos indígenas establecía que los dictámenes periciales expusieran la "diferencia cultural" en casos penales e individuales, la envergadura de las controversias ha

Sentencia de la Segunda Sala Civil del Supremo Tribunal de Justicia del Estado de Chihuahua, Toca 7/2014. 
provocado que los pueblos, litigantes y antropólogos trasladen sus pericias al campo de los derechos colectivos, jurisdiccionales y de género. De los estudios sobre personalidad y criminalidad, hemos pasado al estudio de la territorialidad y el sujeto colectivo, en los que el concepto de diferencia cultural o de cultura se torna insuficiente.

$\mathrm{Al}$ parecer, se está haciendo una costumbre poner en entredicho la utilidad del concepto emblemático de la disciplina. Hay un intento de emancipación de las limitaciones que encierra el contenido y alcance del constructo cultura. Stuart Kirsch, por ejemplo, encuentra amplias complicaciones y preocupaciones para explicar el carácter híbrido y sincrético de las instituciones de los pueblos que ha estudiado en sus informes periciales. Tales complicaciones y preocupaciones se tornan incluso paradojas éticas porque difieren de la información que proporcionan los propios pueblos al intentar esencializar su cultura.

Laura Edith Saavedera Hernández, en un sentido similar, invita a revisar la diversidad de normas que prevalecen en un contexto de conflicto comunitario, en especial en los casos de violencia y disputas de género, ya que las partes invocan y alegan principios y fuentes en un sentido divergente. En estas circunstancias, incluso la pretendida imparcialidad no es suficiente para emitir un dictamen pericial, ya que se requiere un amplio criterio, comprometido con la nivelación de las desigualdades y la eliminación de la violencia.

Esta incomodidad o malestar en la cultura esencialista que el superyó antropológico se niega a rechazar, tiene que ver, a mi parecer, no tanto con una incapacidad de traducción o con que el concepto carezca de valor explicativo, sino más bien con un efecto de estado y de su judicialización, cuyo contenido y valor se vuelve sesgado. Mientras para la antropología la cultura tiene un alcance holístico, universo de significado y de representación de instituciones y formas de ser, incluyendo la capacidad de autonormarse y autogobernarse con normas de varios tipos, para el derecho cobra un sentido vulgar y tyloriano de suma de elementos materiales, conocimientos, costumbres y tradiciones fijas (Tylor, 1993).

Desde esta perspectiva minimalista, la cultura y su sucedáneo, la diferencia cultural, han terminado siendo sinónimo de conglomerado o núcleo de personas que mantienen una sociedad petrificada y esencializada, que debe conservar tradiciones y formas de ser. No sólo detenida en el tiempo, sino además sin derecho a cambiar su pasado. Por esta razón, cuando los pueblos reivindican sus derechos y facultades, anuladas o aminoradas por la colonización, sin apegarse a esta caracterización e idealización, sus demandas se consideran ilegítimas.

En la década de 1970, James Clifford (2001) fue uno de los primeros antropólogos que denunció la forma en que se cancelaron los derechos territoriales de los mashpee, cuando participó en un litigio en el que el juez exigió a ese pueblo que demostrara la continuidad histórica de la jefatura, desde tiempos de la colonización hasta el presente, así como que mantuviera la pureza de sangre, la religiosidad autóctona y la integridad de sus costumbres.

Clifford descalificó la pretensión de exigir pruebas de autenticidad, ya que toda cultura es dinámica y cambiante, mucho más cuando es sometida a procesos de conquista, colonización y aculturación forzada. Sin embargo, ya entrados en el siglo XXI, el requisito de pureza o diferencia sigue siendo una máxima al reclamar reconocimiento de derechos colectivos, como expone Kirsch en su ensayo.

Bajo estas representaciones esencialistas, no sólo persisten el estereotipo y el racismo denunciados por la antropología. Detrás de este discurso y hermenéutica de lo "meramente cultural", como lo define Judith Butler (1998), se oculta la negación de las reivindicaciones políticas, territoriales y de género. El indio permitido y los derechos permitidos son cultural y políticamente correctos cuando se trata de tradiciones, fiestas, folclor, trajes, leguas. Pero, 
como advertía Renato Rosaldo (1991), si la cultura se transforma y se pone en movimiento, se vuelve sospechosa y falaz. Pretender ubicarse en dos fronteras, reclamar identidades múltiples, cuestionar la hegemonía cultural, espacial o patriarcal es hacer trampa.

Las mujeres y hombres indígenas que pretenden salirse del huacal o estereotipo impuesto por la hegemonía nacional, positivista o machista, son fácilmente descalificados, criminalizados o minimizados en sus derechos. En el ejemplo narrado por Ortiz Elizondo, los tepehuanes que están fuera de su comunidad y varados en una carretera federal son detenidos como sospechosos de un asalto; en el peritaje elaborado por Saavedra Hernández, el derecho comunitario de que la esposa, en caso de divorcio, conserve la casa para proveer de techo y seguridad a los hijos se convierte en una acción penal de despojo contra la familia del marido, y en el artículo de Kirsch, la pretensión de conservar un territorio con una cultura e institucionalidad modificada por el tiempo, y que en ciertos aspectos es similar a la nacional, se transforma en una reivindicación falsa y amañada.

¿Qué concepto de cultura y qué definición de sujeto deben ofrecerse para hacer visible e inteligible al sujeto que disputa sus derechos indígenas?

\section{Los sujetos}

El texto de Kirsch incluido en este número de Desacatos problematiza y trata de resolver algunos de esos disgustos y usos dudosos encasillados en lo meramente cultural. Kirsch incluso va más allá de los usos y abusos del reduccionismo cultural, cuando advierte que tenemos que estar prevenidos de que los mismos actores que exigen derechos colectivos se presentan con frecuencia con una narrativa exegética e integrista, y reproducen las representaciones idealizadas por la sociedad dominante. El antropólogo, entonces, se ve atrapado en la disyuntiva de traducir lo literal del "deber ser" narrado por el sujeto, o interpretar el "ser y hacer" observados en la investigación.

El uso y abuso del esencialismo conllevan otros riesgos, que discutiré en el último punto, pero antes, terminemos de evaluar la cláusula de autenticidad que exigen los gobiernos de los Estados a los pueblos originarios. Como hemos comentado, el indio permitido es el que permanece culturalmente correcto, el que se apega a la tradición y a su pasado, no el que se adapta al cambio; el que permanece campesino, no el que vive en las ciudades; el que conserva su lengua autóctona, no el que utiliza un lenguaje politizado; el que se conforma con su papel y soporta la violencia, no el que decide rehacer su vida y terminar con una relación indeseada; el que permanece diferente, no el que quiere ser un igualado.

Al igual que Clifford (2001), en dos demandas de la CIDH para las que Kirsch ofreció sus informes periciales, los Estados impugnaron la identidad del sujeto. Al respecto, los gobiernos sostuvieron que no había lugar para la reclamación de derechos colectivos que ampara el Convenio 169 de la Organización Internacional del Trabajo (OIT), puesto que los demandantes no satisfacían las características de pueblos indígenas (Gómez, 1995). Para empezar, no hablaban una lengua autóctona sino la nacional, eran adeptos al cristianismo y no a una religión originaria, existían matrimonios mixtos y no endogámicos, explotaban minas y comercializaban productos al exterior y un largo etcétera.

Para responder a estas impugnaciones, Kirsch no cae en el juego de tratar de autenticar, purificar o idealizar una cultura como si estuviera estancada en el tiempo, sino que opta por contraargumentar esas tesis y presenta el sentir de los afectados. Así logra, en primer lugar, evitar que la autoridad antropológica defina desde afuera lo que son o no son los pueblos, y en segundo lugar, al asumir un papel de intermediario, coloca frente a frente los discursos de verdad esgrimidos por los contrincantes. Es decir, más que interpretar o elucubrar sobre una 
definición de cultura, de sujeto diferente o esencializado, Kirsch da expresión al discurso del otro y lo articula para hacerlo legible ante la Corte.

Con esta estrategia comunicacional, el perito respondió a la descaracterización que pretendían los Estados y ofreció la autodescripción y autoadscripción narrada por los propios entrevistados, quienes aclararon que no era posible mantener la lengua materna cuando en las escuelas les prohibían hablarla; que adoptaron la religión cristiana en un contexto de imposición y manipulación; que era imposible no interactuar con la sociedad nacional y realizar alianzas matrimoniales cuando fueron desplazados de manera forzosa de su territorio original hasta en dos ocasiones.

Pese a estas circunstancias, que para los antropólogos serían una aculturación y para los gobiernos una desindianización, para los actores sociales nada justificaba el despojo y la invasión de su territorio. Aun como explotadores de minas, no consideraban justo que se dejara la puerta abierta a las concesiones mineras sin su consentimiento. En términos de un sentido común jurídico, advertían en sus alegatos que no estaban de acuerdo con que sus tierras se convirtieran en reservas ecológicas para proteger animales e inversiones, y que ellos quedaran en estado de indefensión: ¿por qué las tortugas tienen derecho a la tierra pero nuestra gente no? (p. 40).

Kirsch tampoco se atora en la interpretación culturalista y retoma la exigencia de los pueblos nativos para que se considere el respeto a las instituciones políticas, sociales y económicas que mantienen vigentes, con independencia de las tradiciones o costumbres que conserven. A partir de esta tesis, el peritaje se concentra en llamar la atención sobre el trabajo comunal y el sistema de redistribución de las tierras y recursos. Es decir, en mostrar la especificidad del aprovechamiento de los bienes mediante un derecho consuetudinario que se apropia de manera especial el territorio. En esta perspectiva, Kirsch no considera necesario sacralizar ni idealizar un modo de vida para reivindicar derechos, sino simplemente reinvindicar las instituciones propias a las que se refiere el Convenio 169 sobre Pueblos Indígenas.

Su propuesta es elemental pero profunda: no perderse en la descripción densa o en las apologías integristas, sino en la argumentación y reclamación que emana de los propios interesados; concentrase en hacer legible y entendible lo esencial de los derechos, no lo particular de la cultura. En este caso, Kirsch dice que sólo hay dos temas a discutir. Por un lado, la libertad de decidir, y por el otro, el derecho a la propiedad. Con ello se suma al hábito de ir desplazando la narrativa culturalista hacia otra que pondera la capacidad política; la esencialista por otra más realista.

Es un nuevo uso del lenguaje y del peritaje que no podemos menospreciar, pues Kirsch hace todo un tránsito desde el lenguaje emic del actor social, que luego pasa por la interpretación etic de la antropología, y lo aloja, por último, en una explicación receptiva para el lenguaje jurídico. No hay mejor manera de convertirse en traductor de culturas que saber llevar el hilo comunicativo de un punto a otro sin caer en arcaísmos o modismos de la escritura esotérica o profunda que con facilidad encandila a la antropología.

Kirsch logra evitar enamorarse del canto de las sirenas y cambia la narrativa de la empatía o la simpatía por argumentación y sustentación. En la misma línea de Paul Ricoeur (2009), evita confundir el amor con la justicia. Aunque esta asociación parezca extravagante, hay una gran semejanza entre el discurso de alabanza y los mandamientos del amor que imponen las escrituras sagradas. El peritaje, sin dudas, no es el espacio para las alabanzas ni los imperativos que exige una relación sentimental.

En cambio, según Ricoeur (2009), el discurso de la justicia se sustenta en la argumentación y el convencimiento, en la confrontación de ideas y el esclarecimiento de conceptos. En este lance es obvio que la antropología se jalonea entre el ideal de interpretar lo exótico y esotérico o explicar lo objetivo y cotidiano, propósito que persigue la justicia. Por ello en la argumentación, en la comunicación y en 
la traducción se concentran muchos de los esfuerzos y de los usos y costumbres que ahora demandan los dictámenes periciales.

En la centralidad de la traducción avanza también Ortiz Elizondo. En esta ocasión, no esclarece la traducción que debe hacer el antropólogo para el juzgado, sino la traducción que pretende hacer el ministerio público frente al juzgado. En este intento, se suma al impulso de ir más allá de la cultura para preguntarse si la aparente ausencia de factor cultural en un juicio invalida los informes periciales antropológicos. Ésa parece ser la lógica del culturalismo cuando se topa con narcotraficantes armados hasta los dientes: ¿qué tanto puede decir o hacer nuestra disciplina en estos casos, en los que no se observan causales determinadas por las normas comunitarias?

Ortiz Elizondo demuestra que hay mucha tela de donde cortar cuando interviene en el juicio de tres indígenas acusados de asalto y portación de armas. En sus entrevistas se da cuenta de la inmensa distancia entre lo registrado en el expediente y lo narrado por los inculpados. Claro, el habla reportada en el expediente y el dicho expresado por los acusados por lo general difieren, porque un secretario redacta y asienta las declaraciones.

Pero en esta ocasión, la declaración emitida por los acusados y la versión asentada en el expediente sobre el tipo, modelo y características de las armas, así como los tiempos, modos y circunstancias de los hechos, no coincidían en ningún nivel del discurso. A decir del perito, el uso de las horas registrado en la declaración ministerial nada tenía que ver con las nociones de tiempo basadas en los recorridos del sol que referían los detenidos. En cuanto a las armas de fuego, cuando en la entrevista el antropólogo los interrogaba sobre los tipos de armas mencionadas en la acusación, no tenían ni idea de lo que se estaba hablando.

Así las cosas, el habla reportada en el expediente, como dijera Valentin Voloshinov (1992), es un habla domesticada y hegemonizada por quien la traslada a un soporte escrito, lo que convierte una oralidad condicionada culturalmente en una verdad jurídica incuestionable. En este sentido, Ortiz Elizondo insiste en que tampoco se trata de demostrar lo cultural en la comisión del delito, sino de desvelar la competencia lingüística, y sobre todo, las causas motivacionales del delito, muy alejadas del hecho de que las personas esperaran tranquilamente ser detenidas por la policía.

En este trabajo, sale a luz la necesidad de investigar no sólo al sujeto activo, que supuestamente comete un ilícito, sino también los usos y costumbres de los operadores del derecho que, como bien dice el colega, con las manos en la cintura se dedican a fabricar delincuentes y sembrar armas mediante la utilización del lenguaje del ventrílocuo, que reemplaza al de los acusados.

En la discusión y la reflexión que ofrecen Kirsch, Ortiz Elizondo y Saavedra Hernández, queda asentada la inmensa tarea de poner en suspenso, antes que cualquier otra cosa, las premisas epistemológicas de la disciplina. Seguramente no para demolerlas, sino para replantearlas en el contexto de una investigación en diálogo con los actores y el campo judicial. En consecuencia, muy aparte de las preferencias teóricas o metodológicas adoptadas, permanece el imperativo de la interpretación y la traducción. Una interpretación que dé testimonio de los mundos de significado y los universos de discurso. Otros mundos, diría Esther Sánchez (2010), quien no por casualidad dedica uno de sus últimos libros a los dilemas de la comunicación intercultural.

Se trata de un trabajo de filigrana para el que rara vez nos preparamos. Lawrence Rosen (1977) apuntaba, a partir de los primeros peritajes elaborados por antropólogos durante el movimiento por los derechos civiles en Estados Unidos, que parecíamos más preocupados por exponer nuestras teorías que por matizar o adaptar nuestro discurso al contexto jurídico en el que participábamos. La pregunta central radica entonces en qué tanto el esoterismo teórico 
puede conducirnos a un diálogo de sordos o qué tanto el pragmatismo, que sólo traslada o traduce datos, puede convertir a la antropología en una labor meramente técnica o de fedatario de hechos, el otro riesgo que advierte Rosembert Ariza (2010) en la producción pericial.

En el amicus curiae, un género en el que la experiencia de la antropología también puede ser protagonista dentro de la justicia, estos límites se relajan mucho más, y desde mi punto de vista, los riegos y ansiedades reseñados a lo largo de estas líneas se agudizan. Expondré algunas enseñanzas que deja el texto presentado por Aura Estela Cumes Simón en la sección "Testimonios", para ir adelantando algunas reflexiones finales.

\section{Los géneros}

En efecto, el amicus curiae es un género nuevo, un nuevo uso de la antropología. Todo un campo por explorar por el formato abierto, libre y colegiado en el cual suele presentarse. Ofrece la gran ventaja de que no encierra al investigador en preguntas o temas acotados, lo cual le permite analizar cuestiones que rebasan su disciplina y expresar opiniones sobre los efectos generales y hasta filosóficos de una decisión judicial. Este relajamiento, a su vez, corre el riesgo de descentrar la investigación o generalizar los temas acuciosos de la litis y pone en tensión una narración que oscila entre el ensayo y el peritaje, entre la disertación y la argumentación.

El texto de Cumes Simón nos proyecta a esta espiral de dilemas y nos permite mostrar las virtudes y bondades de este género de estudios, pero también los riesgos e inconvenientes. Por ejemplo, en la intención que tuvo el gobierno de Guatemala de anular una resolución comunitaria, la autora pudo hacer un historial de agravios intervencionistas por medio del cual se evidenció la historia de supremacía que la sociedad ladina ha impuesto a los pueblos mayas.
En un amicus curiae, el posicionamiento político se hace permisible y rompe el tabú de que el derecho es un campo de normas en el que lo social o lo contingente no tienen cabida. En este caso, Cumes Simón hace un análisis antropológico de las decisiones judiciales, no sólo a partir de la crítica de las normas, sino del prejuicio y el racismo que encierra un sistema legal.

Sin embargo, este análisis histórico de la hegemonía racial, incontrovertible, y que pasa por denunciar la estigmatización sistemática de la civilización maya, basada en la visión estática y salvaje del otro, no debería dirigirse a describir una versión idílica del mundo indígena. Creo que los conflictos y las crisis que enfrentan los pueblos, de los cuales la violencia y la violación también forman parte, se pueden afrontar de mejor manera si cada parte reconoce lo que le corresponde hacer. Es decir, proponer que el patriarcalismo o el caciquismo son efectos del exterior o que provienen de la sociedad mayor no los disolverá.

Si algo nos han enseñado la producción antropológica y pericial es que el mundo indígena y la sociedad dominante forman parte de un entramado indisoluble, y por lo tanto, se debe trabajar en conjunto para resolver los dilemas de la imposición y la sujeción presentes a ambos lados, ya que vivimos en un mundo de interrelaciones e interlegalidades.

Es innegable que los Estados-nación tienen muy poca intención de modificar su relación con los pueblos originarios, las experiencias aquí mostradas así lo indican, pero no podemos dar por sentado que toda aplicación del saber originario es noble por el simple hecho de ser originario. Ésta es una presunción de verdad que puede aceptarse en teoría, pero debe demostrase en la práctica. Así, todo delito de violación puede ser resuelto de manera diligente cuando las partes se ponen de acuerdo, pero no todo acuerdo es atendido diligentemente.

Me explico, el Estado guatemalteco se entrometió de manera flagrante en las decisiones del pueblo maya cuando quiso revertir una decisión colectiva, 
pero eso no obsta para que se haga un análisis de si el acuerdo realmente satisfizo a las partes ni para que se dialoguen las posibles inconsistencias. Digo esto porque en el caso de los azotes - mencionados por Cumes Simón-, la brujería u otras instituciones cuestionadas desde una visión limitada de los derechos humanos, el antropólogo como perito debe verificar esa satisfacción o acuerdo entre las partes antes de hacer una legitimación general. Una cosa es aceptar que es válido aplicar sanciones basadas en un sistema y un procedimiento consensuado y otra que cualquier tipo de sanción sea válida por sí misma, porque entonces se vuelve manipulable y sujeta a abusos. El caso de las violaciones en contextos de ocupación o simplemente de inconformidad de la víctima llamaría a que el perito hiciera un estudio más profundo. No digo que Cumes Simón no lo haya hecho, pero sí que un caso no salva a todos los demás. Así como las normas no son generalizables, los hechos tampoco pueden serlo.

En fin, la digresión se encamina a tomar en cuenta que el formato del amicus curiae se presta a estas proyecciones y el llamado es a que conozcamos los pros y contras de cada uno de los formatos para lograr la mejor comprensión y solución de una controversia legal.

El trabajo de Saavedra Hernández complementa de manera oportuna estos dilemas sobre la idealización, ya sea del derecho consuetudinario o del derecho positivo. Es muy fácil caer en alguno de los polos y favorecer los derechos colectivos en detrimento de los individuales o los derechos individuales en contra de los colectivos. Saavedra Hernández apunta a la exigencia ética de hacer un trabajo de campo en colaboración con los sujetos, en sentido más estricto, con los sujetos que son víctimas, para modalizar la importancia de un derecho o de otro. Ella denomina a esta postura defensa participativa, que deja en un papel secundario la elucubración solipsista del teórico para hacer una invitación a trabajar a los actores afectados por la opresión, en este caso de género.
En su aportación, también retoma las normas comunitarias que favorecen la conservación del patrimonio para las mujeres que se separan de su marido, sobre todo por motivos de violencia, contra los usos agrarios y positivos que por lo regular protegen la herencia varonil y a quienes ostentan la propiedad vía los papeles. En su peritaje rescata estos principios comunitarios que por lo general tratan de ser ocultados u opacados por la presencia de regulaciones impuestas por las normas de sucesión patriarcal.

Aunque falta conocer el desenlace de este caso, en el que una mujer separada fue acusada penalmente de despojo por pretender quedarse con la casa formada en el matrimonio para dar protección a sus hijos, resulta relevante cómo la autora pondera la necesaria discusión de la variedad de normas prevalecientes antes que descartar a priori una u otras. Es decir, hace un llamado a colocarse e involucrarse en las necesidades de los actores y no sólo a reproducir o replicar el conocimiento "observado", ya que ese tipo de enfoque neutralizado y desinteresado es una falacia.

\section{Coda}

Sin agotar todas las posibilidades que el campo de la investigación pericial ofrece al paradigma de la disciplina, he revisado algunos tópicos novedosos que proponen los ensayos recolectados. Es inobjetable que en la experiencia de elaboración de dictámenes para el aparato judicial se retomen algunas normas clásicas, pero en otras se están confirmando ciertos usos y costumbres ajenas al canon aceptado.

El uso y costumbre, que sin duda ha regresado, consiste en retomar el estudio del derecho no sólo como un asunto de interés científico y académico, sino como un retorno a las preocupaciones sobre el colonialismo. Ahora no se dirige a testificar ni justificar la absorción de un sistema legal sobre otro, sino a cómo resolver la convivencia y coordinación entre sistemas jurídicos. 
En este trance, resurge la inexorable evidencia de que el antropólogo, por más que quiera sustraerse al tiempo en el que vive, resulta un sujeto ubicado en los contextos políticos y sociales. En los informes periciales antropológicos, lo quiera o no, opta por dar una opinión que puede inclinar la balanza y comprometer el destino de una persona o un pueblo. Esto tiene que ver con la responsabilidad de su labor investigadora, que esta vez no puede dejar entre paréntesis, sino al contrario, debe expresarla de manera asertiva en las conclusiones o de otra manera no será un dictamen.

Lo anterior no deja de ser paradójico porque, como ha planteado César Rodríguez (2016), la investigación-acción resultante del acompañamiento de procesos sociales, en este caso legales, convierte casi de manera inevitable al científico social en un investigador-actor, que ejerce un oficio anfibio entre conocimiento y colaboración, que tiene entre sus manos un instrumento que lo compromete con el mundo y los actores sociales, del cual no puede zafarse a menos que renuncie a protestar su cargo de perito.

La observación participante se convierte entonces en participación acompañante y la investigación de campo en la observación de varios campos en confrontación que no puede eludir interpretar, lo cual nos regresa al planteamiento inicial de por qué los peritos no somos unos antropólogos normales. D

\section{Bibliografía}

Ariza, Rosembert, 2010, "Peritazgo socio-antro-jurídico y administración de justicia intercultural en Colombia", en Instituto Interamericano de Derechos Humanos, Acceso a la justicia de los pueblos indígenas: los peritajes culturales y la visión de pobreza desde su cosmovisión, Instituto Interamericano de Derechos Humanos, San José, pp. 13-33.

Butler, Judith, 1998, “El marxismo y lo meramente cultural”, en New Left Review, núm. 227, pp. 109-121.

Castillo Farreras, José, 1973, Las costumbres y el derecho, Secretaría de Educación Pública, México.

Clifford, James, 2001, Dilemas de la cultura. Antropología, literatura y arte en la perspectiva posmoderna, Gedisa, Barcelona.

Escalante Betancourt, Yuri, 2015, El racismo judicial en México, Juan Pablos, México.

Foucault, Michel, 2001, Los anormales, Fondo de Cultura Económica, México.

Galarza, Joaquín, 1979, Estudios de escritura indígena tradicional azteca-náhuatl, Archivo General de la Nación, México.

Gómez, Magdalena, 1995, Derechos indigenas. Lectura comentada del Convenio 169 de Organización Internacional del Trabajo, Instituto Nacional Indigenista, México.

Hernández Castillo, Rosalva Aída y Héctor Ortiz Elizondo, 2012, “Asunto: Violación de una indígena me’phaa por miembros del Ejército Mexicano. Presentado ante la Corte Interamericana de Derechos Humanos. Abril-mayo de 2010. Una historia de agravios y desagravios: el Ejército Mexicano ante la colDH", en Boletín Colegio de Etnólogos y Antropólogos Sociales, año 2012, pp. 67-81.

Holmes, William Henry, 1907, Biographical Memoir of Lewis H. Morgan, 1818-1888, Press of Judd \& Detweiler, Washington, D. C. Lévi-Strauss, Claude, 2014, Todos somos canibales, Fondo de Cultura Económica, México.

Martínez Marín, Carlos, 1976, “La etnohistoria, un intento de explicación”, en Anales de Antropología, vol. 13, núm. 1, pp. $172-181$.

Mena, Ramón, 1903, "Criminalidad indígena”, en Etnografías del estado de Puebla, Talleres de la Imprenta Guadarrama, Puebla.

Ricoeur, Paul, 2009, Amor y justicia, Siglo XXI Editores, México.

Rodríguez Garavito, César, 2016, "Investigación anfibia. Los derechos humanos y la investigación-acción en un mundo multimedia”, en César Rodríguez Garavito, Extractivismo versus derechos humanos. Crónicas de los nuevos campos minados en el Sur Global, Siglo XXI Editores, Buenos Aires, pp.

Rosaldo, Renato, 1991, Cultura y verdad. Nueva propuesta de análisis social, Grijalbo, México.

Rosen, Lawrence, 1977, “The Anthropologist as Expert Witness”, en American Anthropologist, vol. 79, núm. 3, pp. 555-578.

Sánchez Botero, Esther, 2010, El peritaje antropológico. Justicia en clave cultural, Deutsche Gesellschaft für Technische Zusammenarbeit/ Cooperación Técnica Alemana/ProFis, Bogotá.

Tylor, Edward B., 1993, "Cultura primitiva”, en Paul Bohannan y Mark Glazer (eds.), Antropología. Lecturas, McGraw-Hill, Madrid, pp. 64-78.

Voloshinov, Valentin, 1992, El marxismo y la filosofía del lenguaje, Alianza, Madrid.

\section{Archivo}

Archivo Manuel Gamio (AMG), Biblioteca del Museo Nacional de Antropología, México. 